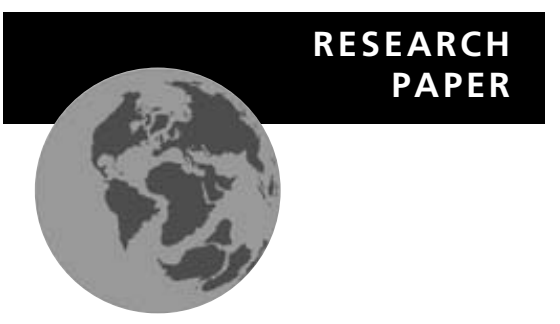

\title{
The latitudinal gradient of beta diversity in relation to climate and topography for mammals in North America
}

\author{
Hong Qian ${ }^{1 \star}$, Catherine Badgley ${ }^{2}$ and David L. Fox ${ }^{3}$
}

${ }^{1}$ Research and Collections Center, Illinois State Museum, 1011 East Ash Street, Springfield, IL 62703, USA, ${ }^{2}$ Museum of Paleontology, University of Michigan, 1109 Geddes Road, Ann Arbor, MI 48109, USA, ${ }^{3}$ Department of Geology and Geophysics, University of Minnesota, 310 Pillsbury Drive, Minneapolis, MN 55455, USA

${ }^{*}$ Correspondence: Hong Qian, Research and Collections Center, Illinois State Museum, 1011 East Ash Street, Springfield,

IL 62703, USA.

E-mail: hqian@museum.state.il.us

\begin{abstract}
Aim Spatial turnover of species, or beta diversity, varies in relation to geographical distance and environmental conditions, as well as spatial scale. We evaluated the explanatory power of distance, climate and topography on beta diversity of mammalian faunas of North America in relation to latitude.
\end{abstract}

Location North America north of Mexico.

Methods The study area was divided into 313 equal-area quadrats $(241 \times 241 \mathrm{~km})$. Faunal data for all continental mammals were compiled for these quadrats, which were divided among five latitudinal zones. These zones were comparable in terms of latitudinal and longitudinal span, climatic gradients and elevational gradients. We used the natural logarithm of the Jaccard index $(\ln J)$ to measure species turnover between pairs of quadrats within each latitudinal zone. The slope of $\ln J$ in relation to distance was compared among latitudinal zones. We used partial regression to partition the variance in $\ln J$ into the components uniquely explained by distance and by environmental differences, as well as jointly by distance and environmental differences.

Results Mammalian faunas of North America differ more from each other at lower latitudes than at higher latitudes. Regression models of $\ln J$ in relation to distance, climatic difference and topographic difference for each zone demonstrated that these variables have high explanatory power that diminishes with latitude. Beta diversity is higher for zones with higher mean annual temperature, lower seasonality of temperature and greater topographic complexity. For each latitudinal zone, distance and environmental differences explain a greater proportion of the variance in $\ln J$ than distance, climate or topography does separately.

Main conclusions The latitudinal gradient in beta diversity of North American mammals corresponds to a macroclimatic gradient of decreasing mean annual temperature and increasing seasonality of temperature from south to north. Most of the variance in spatial turnover is explained by distance and environmental differences jointly rather than distance, climate or topography separately. The high predictive power of geographical distance, climatic conditions and topography on spatial turnover could result from the direct effects of physical limiting factors or from ecological and evolutionary processes that are also influenced by the geographical template.

\section{Keywords}

Beta diversity, climate, Jaccard index, latitudinal diversity gradient, macroecology, mammalian faunas, spatial turnover.

\section{INTRODUCTION}

The distribution of species ranges across regions and continents determines large-scale diversity gradients as well as local species richness of floras and faunas. Patterns of species richness and turnover vary across the earth at multiple spatial scales (Hutchinson, 1959; Gaston, 2000; Hillebrand, 2004). At large scales, the most familiar of these patterns is the latitudinal diversity gradient (Pianka, 1966; Rosenzweig, 1995; Willig et al., 2003; Mittelbach et al., 2007). At a specified scale, variation in spatial 
turnover in relation to the environmental properties of the landscape provides evidence for causal mechanisms influencing recurrent patterns in spatial turnover of species, or beta diversity (Whittaker, 1977). Beta diversity can be measured with respect to geographical distance or differences in environmental variables (e.g. Qian et al., 2005; Gaston et al., 2007; Qian \& Ricklefs, 2007).

Studies of beta diversity, while less numerous than those of species richness per se, focus on the geographical and environmental contexts in which species composition changes by addition or subtraction of species from local assemblages. Evaluation of these relationships provides fundamental insights into species richness in space and time (Rosenzweig, 1995). However, studies of beta diversity at the continental scale are few, and most of these have sought to determine whether the focal taxonomic group exhibits a latitudinal gradient in beta diversity without evaluating the contributions of the physical context - climatic and physiographic variables - to beta diversity. For many widely distributed groups of organisms, species inhabiting temperate and polar regions have larger geographical ranges than do tropically situated species - the pattern known as Rapoport's rule (Stevens, 1989). A corollary is that species turnover across the landscape decreases at higher latitudes, leading to the expectation of a latitudinal gradient in beta diversity. Studies of beta diversity thus far document patterns that vary in relation to taxonomic group, taxonomic level, spatial scale and geographical region. For example, Koleff et al. (2003) reported increased species turnover with distance for New World owls (Strigidae and Tytonidae) closer to the equator. For birds of the world, Gaston et al. (2007) evaluated turnover in relation to latitude, species richness and environmental conditions. Turnover with distance in relation to latitude showed a variable pattern. In the Northern Hemisphere, turnover was highest at low latitudes, peaking at $20^{\circ} \mathrm{N}$, and declining up to $60^{\circ} \mathrm{N}$, then rising at higher latitudes. Qian \& Ricklefs (2007) found that beta diversity in relation to distance for North American vascular-plant assemblages decreased from low to high latitudes, representing a gradient of decreasing temperature and increasing seasonal variation in temperature, and within latitudinal zones from species to genera to families. Among studies of North American mammals, Pagel et al. (1991) documented a positive relationship between geographical range size and latitude, as well as a negative relationship between range size and longitude - implying higher turnover at lower latitudes and in western regions. Arita (1997) documented high beta diversity in relation to environmental heterogeneity (elevation and climatic variability) for Mexican mammals. Both Kaufman \& Willig (1998) and Rodríguez \& Arita (2004) found that beta diversity of North American mammals in relation to distance decreased with increasing latitude among non-volant mammals, but not among bats. In contrast, Stevens \& Willig (2002) documented a latitudinal gradient of beta diversity with distance for New World bat faunas, with the highest values at low latitudes.

In this study, we analyse North American mammalian faunas across five latitudinal zones covering North America north of Mexico (Fig. 1). We evaluate the contributions of climatic and physiographic variables and geographical distance to turnover of mammal species. Variation in beta diversity with respect to

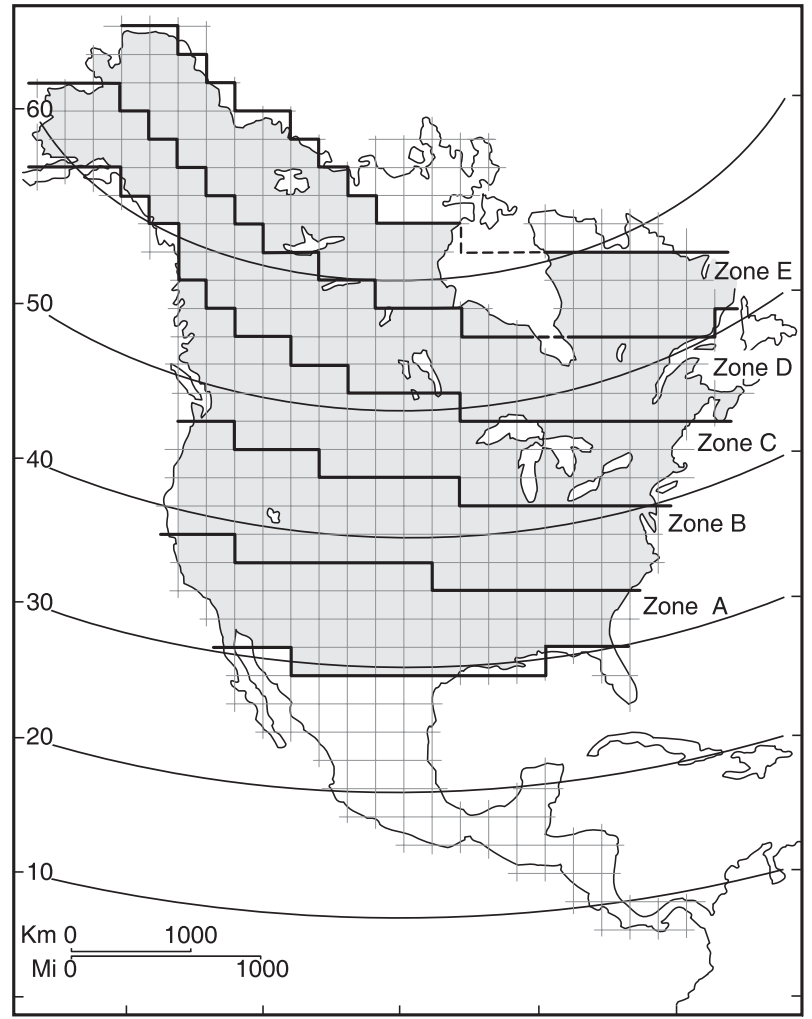

Figure 1 Division of North America into five latitudinal zones.

environmental factors provides evidence for differences in habitat specialization, whereas variation in beta diversity with respect to geographical distance, independent of environmental conditions, suggests differences in dispersal limitation (Condit et al., 2002; Svenning \& Skov, 2004) as well as historically different geographical sources of species (such as Nearctic and Neotropical realms). Environmental conditions and distance also interact as potential influences, since environmental conditions usually differ more among sites at greater distances along latitudinal and longitudinal gradients in North America.

The major objectives of this study are to determine whether beta diversity of mammalian assemblages in North America varies systematically with latitude and to assess the relative importance of climatic and topographic variables as well as geographical distance in predicting the beta diversity of mammalian faunas. We evaluate eight climatic and two physiographic variables variables that have demonstrated significance in earlier studies of North American mammal diversity gradients (Currie, 1991; Badgley \& Fox, 2000). Faunas are compared within latitudinal zones and the zones themselves are compared in order to characterize the latitudinal gradient in beta diversity. The primary analyses are done at the species level, but we illustrate beta diversity at the genus and family levels for comparison with other studies of extant mammals (e.g. Kaufman, 1995) and with patterns in the fossil record that are often analysed at higher taxonomic levels (e.g. Janis et al., 2002; Jernvall \& Fortelius, 2002).

The scale of this analysis is a grid of equal-area quadrats, $241 \mathrm{~km}$ (150 miles) on a side, based on the grid used by Simpson (1964) in his classic study of the species density of North American 
mammals. At this scale of analysis, differences among regions are characterized well by general macroclimate and physiography rather than more localized variables. North America (north of Mexico) has a broad longitudinal span from relatively low $\left(c .30^{\circ}\right)$ to high $\left(>80^{\circ}\right)$ latitude, transected by physiographic features oriented generally from north to south - the Appalachian Mountains in the east and the American Cordillera in the west. North of $\sim 30^{\circ} \mathrm{N}$, variation in continental area does not confound interpretations of richness-based metrics. Thus, North America north of Mexico is an ideal testing ground for the relationship between beta diversity and latitude.

In contrast to previous analyses of spatial turnover of North American mammals, this study explicitly evaluates distance and environmental conditions as predictors of faunal differences. We include all continental mammals, in contrast to studies separating bats from non-volant mammals, because north of $30^{\circ} \mathrm{N}$, most mammalian faunas have fewer than 10 species of bats (Rodríguez \& Arita, 2004). Also, beta diversity is quantified in a different way from other studies, permitting us to evaluate latitudinal and longitudinal trends. Variance partitioning reveals the unique as well as joint contributions of distance and environmental factors in predicting beta diversity. Because a full understanding of the latitudinal gradient in beta diversity cannot be achieved until many groups of organisms have been examined, our study adds to the literature and offers an opportunity for comparing the latitudinal gradient in beta diversity between plants (Qian \& Ricklefs, 2007) and animals.

\section{MATERIAL AND METHODS}

Mammalian species richness and some environmental variables were taken from the data set of Badgley \& Fox (2000). In their study, North America was divided into 388 equal-area quadrats $(241 \times 241 \mathrm{~km})$ on a Lambert equal-area projection, and species lists for each quadrat were compiled from species range maps of Hall (1981) and more recent sources (see Badgley \& Fox, 2000, for details of data compilation). Quadrats occupied by less than $25 \%$ land area, along coastal regions, were omitted. Since the analytical method involves evaluating beta diversity across latitudinal zones of comparable magnitude, we excluded quadrats located south of $30^{\circ} \mathrm{N}$ because the span of longitudes is quite small. We divided North America north of $30^{\circ} \mathrm{N}$ into five latitudinal zones (Fig. 1). Isopleths of temperature run subparallel with latitude but tend to shift northward from east to west, and this shift is more apparent at more northern latitudes. For example, the southern boundary of the boreal zone shifts over $15^{\circ}$ of latitude from east to west (Barbour \& Billings, 1999). We constructed latitudinal zones such that the differences in temperature between eastern and western parts of each zone were minimized while keeping the latitudinal spans comparable among zones. We divided the temperate region into three zones and the boreal and arctic region into two zones (Fig. 1). We excluded a few quadrats located in the arctic region in order to make the latitudinal span of the two northernmost zones consistent. For the three southernmost zones, the latitudinal span of each zone narrows eastwards, but this trend occurs in all the latitudinal zones. Each quadrat was assigned to a zone according to its midpoint latitude. Figure 1 illustrates the latitudinal zones and the 313 quadrats included in our analyses.

For each latitudinal zone, we calculated a Jaccard index of faunal similarity for pairs of quadrats. We used the Jaccard index because it is commonly used in ecological analyses, including those of beta diversity (Nekola \& White, 1999; Qian et al., 2005; Gaston et al., 2007; Qian \& Ricklefs, 2007), and because we wanted to compare this analysis for North American mammals with that of Qian \& Ricklefs (2007) for North American vascular plants, in which the Jaccard index was used. The Jaccard index $(J)$ is defined as $J=a /(a+b+c)$, where $a$ is the number of taxa shared between two localities and $b$ and $c$ are the numbers of taxa unique to each locality (Legendre \& Legendre, 1998); values of $J$ range from 0 to 1 . We calculated the Jaccard index for faunas from all pairs of quadrats within each zone in order to characterize the degree of turnover within each latitudinal zone. Calculations were done separately for species, genera and families based on the mammalian taxonomy of Wilson \& Reeder (1993).

We regressed the natural logarithm of $J(\ln J)$ on spatial distance between quadrat pairs in each latitudinal zone and used the absolute value of slope of the $\ln J$-distance relationship as a measure of spatial beta diversity, or distance decay of similarity (Nekola \& White, 1999). The distance between pairs of quadrats was measured between their centroids. Since $n$ quadrats in a latitudinal zone result in $n(n-1) / 2$ pairs of quadrats, taking $n(n-1) / 2$ as the number of degrees of freedom can increase the rate of Type I errors because each quadrat is used in multiple comparisons, and thus the significance of a statistical test can be inflated. To address this problem, we used a permutation approach to adjust probabilities of statistical inference. The approach that we used to determine the significance level for each regression model was developed by Legendre et al. (1994) and was implemented in Permute! Version 3.4 (available online at http:// www.bio.umontreal.ca/casgrain/en/labo/permute/index.html). All $P$ values were determined from 9999 permutations.

In order to evaluate the relationship between $\ln J$ for species and differences in physiographic and climatic conditions among quadrats (environmental beta diversity), we compiled data for 10 environmental variables for each quadrat: mean elevation, topographic relief and eight climatic variables. Data for elevation (m) and relief ( $\mathrm{m}$ ) are from Badgley \& Fox (2000). The eight climatic variables and their units of measurement are: (1) mean annual temperature $\left(\mathrm{TEMP}_{\mathrm{ann}},{ }^{\circ} \mathrm{C}\right),(2)$ mean temperature of the coldest month $\left(\mathrm{TEMP}_{\min },{ }^{\circ} \mathrm{C}\right),(3)$ mean temperature of the warmest month $\left(\mathrm{TEMP}_{\max },{ }^{\circ} \mathrm{C}\right)$, (4) seasonality of temperature $\left(\mathrm{TEMP}_{\text {max }}-\mathrm{TEMP}_{\text {min }}=\mathrm{TEMP}_{\text {seas }}{ }^{\circ} \mathrm{C}\right),(5)$ mean annual precipitation $\left(\mathrm{PPT}_{\mathrm{ann}}, \mathrm{mm}\right),(6)$ seasonality of precipitation (wettest month precipitation minus driest month precipitation, $\mathrm{PPT}_{\text {seas }}, \mathrm{mm}$ ), (7) annual actual evapotranspiration (AET, mm), (8) annual potential evapotranspiration (PET, $\mathrm{mm}$ ). These variables represent important aspects of climate and have high predictive power for species richness of mammals and plants over broad spatial scales (e.g. Currie, 1991; Badgley \& Fox, 2000; Qian et al., 2005; Qian \& Ricklefs, 2007). We obtained temperature and precipitation data from New et al. (1999) and evapotranspiration data from Ahn \& 
Table 1 Taxonomic richness and species turnover for different latitudinal zones.

\begin{tabular}{|c|c|c|c|c|c|}
\hline & \multicolumn{5}{|c|}{ Latitudinal zone } \\
\hline & A & B & $\mathrm{C}$ & $\mathrm{D}$ & $\mathrm{E}$ \\
\hline Total family richness & 28 & 25 & 23 & 18 & 17 \\
\hline Total genus richness & 98 & 86 & 74 & 57 & 45 \\
\hline Total species richness & 288 & 252 & 162 & 108 & 81 \\
\hline Mean species richness per quadrat & 83.2 & 81.8 & 68.8 & 49.2 & 37.7 \\
\hline SD of species richness per quadrat & 22.9 & 17.5 & 8.0 & 7.0 & 6.8 \\
\hline Total/mean species richness & 3.46 & 3.08 & 2.35 & 2.20 & 2.15 \\
\hline Mean $\ln J$ for species & -1.104 & -0.983 & -0.629 & -0.546 & -0.642 \\
\hline Variance of $\ln J$ for species & 0.335 & 0.234 & 0.079 & 0.079 & 0.094 \\
\hline Slope of $\ln J$ for species versus distance & -0.681 & -0.448 & -0.224 & -0.169 & -0.165 \\
\hline No. of quadrats included & 50 & 59 & 58 & 78 & 68 \\
\hline
\end{tabular}

$\ln J$, natural logarithm of the Jaccard index.

Tateishi (1994). We performed a principal components analysis on the correlation matrix of the eight climatic variables in order to reduce the number of variables in further analyses and to account for collinearity among climatic variables (Tables 2, 3). In order to compare species turnover with environmental differences, we calculated the difference in elevation, relief and climate variables between pairs of quadrats. For the physiographic variables, differences were calculated from the raw data. For climatic variables, differences were calculated from the scores on each of the first four principal component (PC) axes. For each latitudinal zone, $\ln J$ was regressed on the difference in PC scores for each pair of quadrats. For each regression model, the standardized regression coefficients indicated which PC axis made the greatest contribution to the regression model. A set of similar regression analyses was performed with the topographic variables as predictors of $\ln J$. A third set of regression analyses included both climatic (PC scores) and topographic variables as predictors of $\ln J$. These regression models were compared for each latitudinal zone (Table 4).

Finally, we conducted a series of partial regressions (Legendre \& Legendre, 1998) to partition the variance in $\ln J$ into the components uniquely explained by spatial distance, uniquely explained by environmental difference, explained jointly by distance and environmental difference, and explained by none of these variables. In each partial regression, the spatial distance between quadrats was contrasted with a set of variables representing environmental difference, including the difference between scores of the first four PCs and differences in elevation and topographic relief for each pair of quadrats. Each latitudinal zone was analysed separately.

\section{RESULTS}

\section{Latitudinal gradient in taxonomic richness and turnover in relation to spatial distance}

Together the five latitudinal zones have 363 species of extant mammals, belonging to 28 families and 109 genera. Family, genus and species richness in each latitudinal zone decreases substantially with increasing latitude (Table 1). While mean species richness per quadrat also decreases with latitude (Table 1), the decline is smaller than for total species richness. The richness ratio of Zone A to Zone $\mathrm{E}$ is 3.6 for entire zones and 2.2 for quadrats. Also, the ratio of total to mean species richness within each zone decreases from zones A to E (Table 1). These patterns imply that faunas at higher latitudes are more similar and that spatial turnover is lower at higher latitudes.

Beta diversity of mammalian faunas decreases with latitude at the species, genus and family levels, although the differences between latitudinal zones are much lower for genus and family than for species (Fig. 2). (Pairs of quadrats with similar faunas have low negative values of $\ln J$ and pairs with dissimilar faunas have high negative values.) Several patterns emerge. First, the mean value of $\ln J$ within a zone increases from -1.104 in Zone $\mathrm{A}$ to -0.546 in Zone $\mathrm{D}$ and then decreases to -0.642 in Zone E (Table 1). Thus, on average, faunas are less similar at lower latitudes than at higher latitudes, but the trend changes slightly in the northernmost zone. Second, the variance of $\ln J$ within a zone decreases with increasing latitude from 0.335 in Zone A to 0.079 in zones $\mathrm{C}$ and $\mathrm{D}$ (Table 1). Zone $\mathrm{E}$ has a slightly higher value (0.094). The general pattern indicates that the more northerly zones contain quadrats that are more homogeneous in taxonomic composition. Third, the slope of the relationship between $\ln J$ and distance for all pairs of quadrats within each zone (Fig. 2) ranges from -0.681 in Zone A to -0.165 in Zone $\mathrm{E}$, with monotonically declining slope values in between. The slopes are fairly shallow for zones $\mathrm{C}, \mathrm{D}$ and $\mathrm{E}$ and substantially steeper for zones A and B (Fig. 3a), suggesting that a major decrease in spatial turnover with distance occurs between zones $\mathrm{B}$ and $\mathrm{C}$. In addition, $\ln J$ reaches much lower values for zones A and B than for zones C-E. Thus, faunas differ more in relation to longitude for zones at lower latitudes. Regression models using the spatial distance separating pairs of quadrats to predict $\ln J$ for species explained from $82.8 \%$ to $49.8 \%$ of the variance in $\ln J$ in zones A to $\mathrm{E}$, respectively (Table 4 ). 

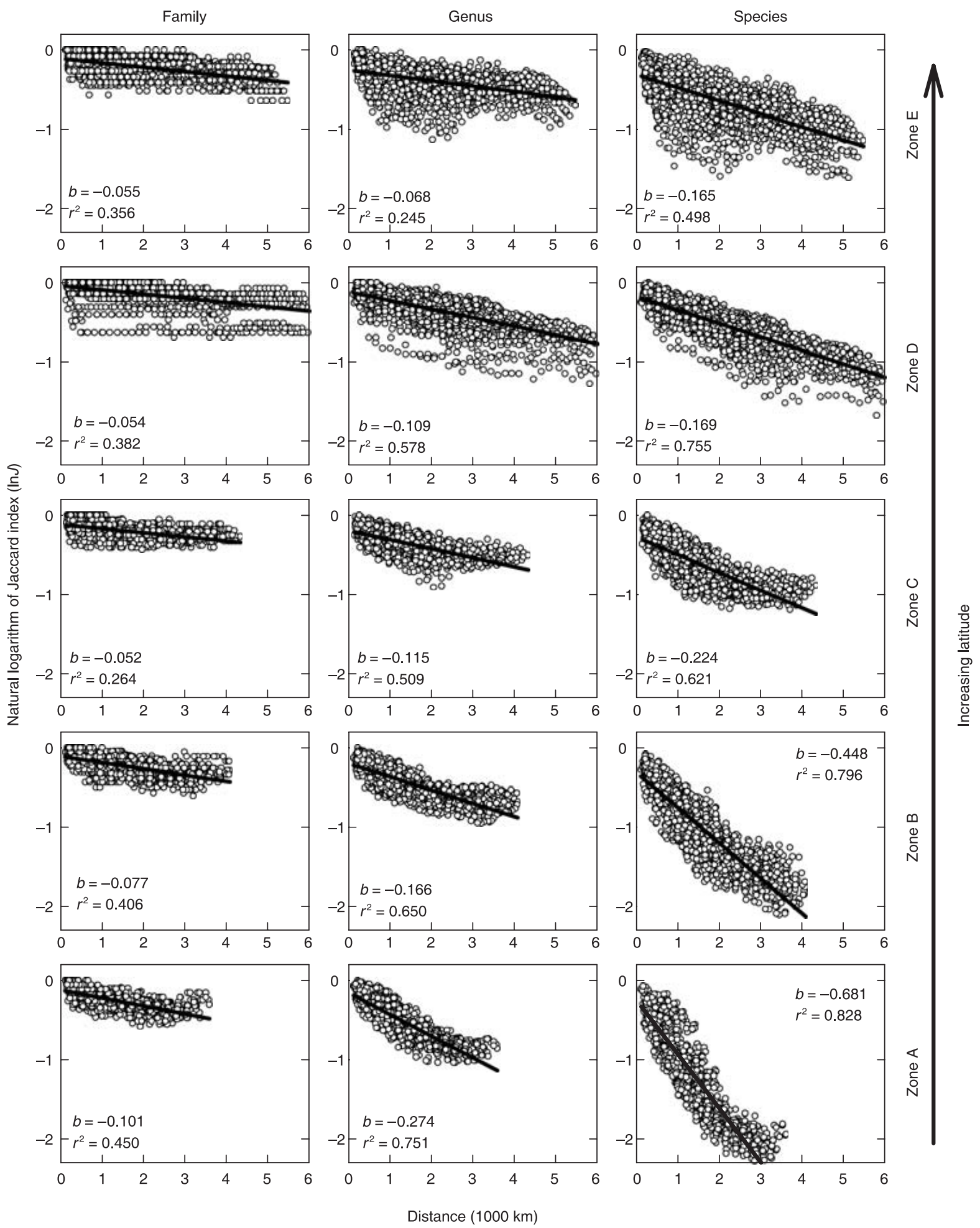

Figure 2 Relationship between the natural logarithm of the Jaccard index of similarity $(\ln J)$ and geographical distance for each of three taxonomic levels (family, genus and species) within each of five latitudinal zones (A to E). Slopes ( $b$ ) were estimated from linear least square regressions. All the regressions were significant at $P<0.001$.

\section{Species turnover in relation to environmental variables}

In the principal components analysis, the climatic variables are well represented by the first four PC axes, which account for
97.9\% of the variance (Table 2). The first axis (PC 1) contrasts quadrats having high values of mean annual temperature, monthly minimum temperature, monthly maximum temperature and both potential and actual evapotranspiration with quadrats 

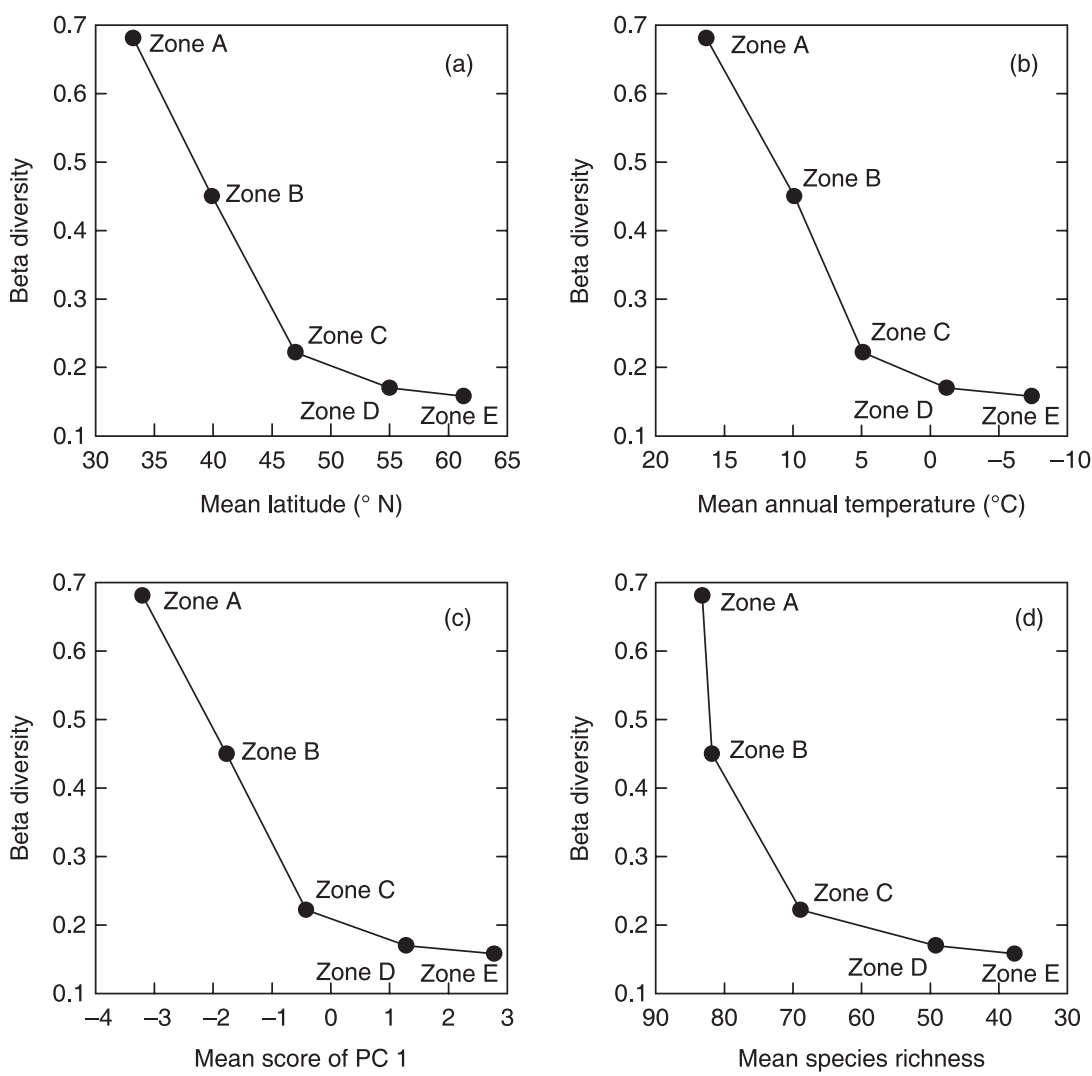

Figure 3 Relationship between beta diversity at the species level, measured as the absolute value of slope of $\ln J$ in relation to distance from Fig. 2, and (a) mean latitude, (b) mean annual temperature, (c) mean PC 1 score (first principal component of climatic data) and (d) mean species richness per quadrat of each latitudinal zone.

having high seasonality of temperature. This climatic gradient is strongly correlated with latitude (as in Badgley \& Fox, 2000). The mean value of scores on PC 1 for quadrats in each zone increases from Zone A to Zone E, and the variation among quadrats tends to decrease from Zone A to Zone E (Table 3). The second axis (PC 2) contrasts quadrats with high versus low values of annual precipitation and seasonality of precipitation (Table 2 ). The mean value of scores on PC 2 shows a weak latitudinal gradient, and the variation among quadrats tends to decrease from zones $\mathrm{A}$ to E (Table 3). PC 3 highlights climatic seasonality by contrasting quadrats having high seasonality of temperature and high annual actual evapotranspiration with quadrats having high seasonality of precipitation (Table 2). PC 4 represents additional variation in seasonality of temperature and precipitation. Neither the mean score on PC 3 and PC 4 nor variation in these scores covaries with latitude (Table 3). The variation (standard deviation) in quadrat scores on PC 1 and PC 2 within latitudinal zones decreases from Zone A to Zone E (Table 3). Since these axes represent most (83\%) of the variance in the eight climatic variables (Table 2), this trend indicates that the overall climatic variation among quadrats from each latitudinal zone decreases from lower to higher latitudes.

Multiple regression of $\ln J$ on the paired differences in scores on PC 1 to PC 4 shows different relationships for different latitudinal zones. The difference in PC scores between pairs of quadrats is a measure of difference in current climatic conditions for those quadrats. The variance in $\ln J$ explained by the differences in climatic conditions decreases with increasing latitude from $81.5 \%$ to $36.2 \%$ (Table 4 ), and the climatic differences contributing most to the regression model for each latitudinal zone vary with latitude (Table S1 in Supporting Information). The differences in PC scores explain less variance in $\ln J$ at higher latitudes.

Regression models using topographic relief and elevation also vary among different latitudinal zones. From low to high latitudes, the amount of variance explained in multiple regression of $\ln J$ on the differences in relief and elevation between quadrats decreases from $63.1 \%$ for Zone A to $5.6 \%$ for Zone E (Table 4). In most latitudinal zones, differences in topographic relief contribute more to the prediction of $\ln J$ than do differences in elevation (Table S1 in Supporting Information). The decline in explained variance with increasing latitude covaries with the decrease in elevation of vegetation zones at higher latitudes. The latitudinal timberline in North America lies near the boundary between zones D and E. Thus, for these latitudinal zones, differences in elevation and relief do not correspond to substantial changes in life zones.

Regression models combining climatic and topographic variables show a slight improvement in the amount of variance explained in $\ln J$ for each latitudinal zone, as well as a latitudinal gradient in the amount of variance explained (Table 4). The differences in PC scores and topographic variables together explain from $86.6 \%$ to $40.1 \%$ of the variance in $\ln J$ for zones A to E (Table 4). Over the five latitudinal zones, different climatic and physiographic conditions make substantial contributions to the prediction of beta diversity. The northward trend of decreasing variance explained in $\ln J$ by climatic and topographic variables parallels the latitudinal trend of decreasing variation in these environmental variables (Tables 5 \& S2). 
Table 2 Results of principal components (PC) analysis of climatic variables for quadrats $(n=313)$ in five latitudinal zones, based on the correlation matrix.

\begin{tabular}{|c|c|c|c|c|}
\hline & PC 1 & PC 2 & PC 3 & PC 4 \\
\hline Eigenvalue & 5.32 & 1.33 & 0.70 & 0.48 \\
\hline Per cent of variance & 66.54 & 16.56 & 8.75 & 6.00 \\
\hline $\begin{array}{l}\text { Cumulative per cent } \\
\text { of variance }\end{array}$ & 66.54 & 83.10 & 91.85 & 97.85 \\
\hline \multicolumn{5}{|l|}{ Correlation with PC axis } \\
\hline $\mathrm{TEMP}_{\mathrm{ann}}$ & -0.97 & 0.19 & 0.01 & -0.07 \\
\hline $\mathrm{TEMP}_{\text {min }}$ & -0.96 & 0.18 & 0.18 & 0.09 \\
\hline $\mathrm{TEMP}_{\max }$ & -0.88 & 0.28 & -0.19 & -0.29 \\
\hline $\mathrm{TEMP}_{\text {seas }}$ & 0.82 & -0.06 & -0.43 & -0.37 \\
\hline $\mathrm{PPT}_{\mathrm{ann}}$ & -0.61 & -0.68 & -0.23 & 0.30 \\
\hline $\mathrm{PPT}_{\text {seas }}$ & -0.35 & -0.75 & 0.41 & -0.38 \\
\hline AET & -0.80 & -0.29 & -0.48 & 0.01 \\
\hline PET & -0.94 & 0.25 & 0.03 & -0.12 \\
\hline
\end{tabular}

Climatic variables are: mean annual temperature $\left(\mathrm{TEMP}_{\mathrm{ann}},{ }^{\circ} \mathrm{C}\right)$, mean temperature of the coldest month $\left(\mathrm{TEMP}_{\min },{ }^{\circ} \mathrm{C}\right)$, mean temperature of the warmest month $\left(\right.$ TEMP $\left._{\max },{ }^{\circ} \mathrm{C}\right)$, seasonality of temperature $\left(\mathrm{TEMP}_{\max }-\mathrm{TEMP}_{\text {min }}=\mathrm{TEMP}_{\text {seas }}{ }^{\circ} \mathrm{C}\right)$, annual precipitation $\left(\mathrm{PPT}_{\text {ann }}\right.$, $\mathrm{mm}$ ), seasonality of precipitation (wettest month precipitation minus driest month precipitation, $\mathrm{PPT}_{\text {seas }}, \mathrm{mm}$ ), annual actual evapotranspiration (AET, $\mathrm{mm}$ ), annual potential evapotranspiration (PET, mm).

When spatial distance, climatic conditions and topographic variables were simultaneously included in a regression model, the amount of variance explained in $\ln J$ improved substantially across all latitudinal zones (Table 4). These regression models explain $93.5 \%$ of the variance in $\ln J$ for Zone A and $57.4 \%$ for Zone E, with intermediate values for zones B, C and D (Table 4).

\section{Variance partitioning among distance and environmental variables}

The partitioning of variance explained by spatial distance alone, by environmental variables (climate and topography) alone and by distance and environmental variables jointly varies across latitudinal zones (Fig. 4). For Zone A, the greatest amount of variance $(75.9 \%)$ is explained jointly by distance and environmental variables, while environmental variables alone explain

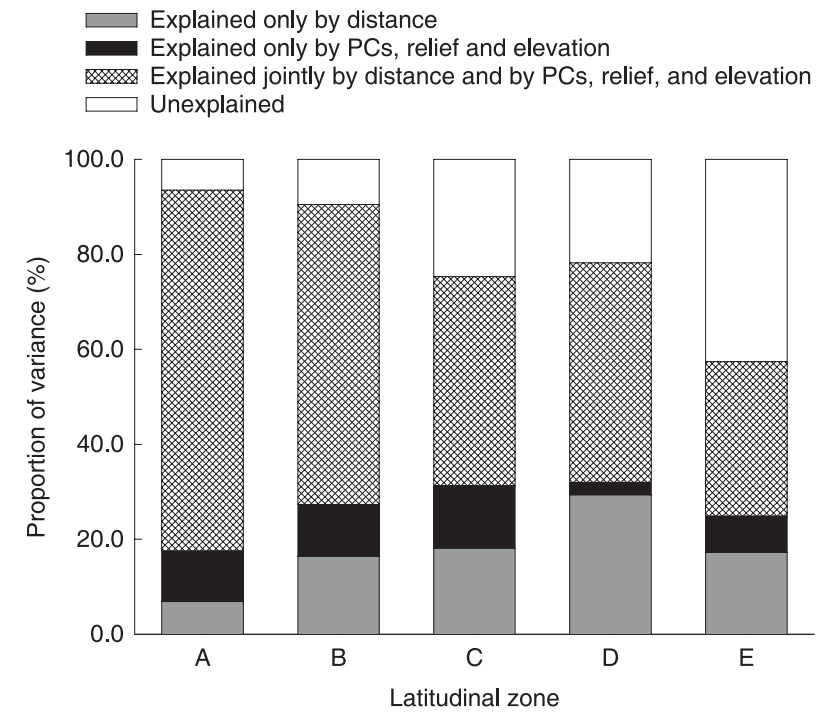

Figure 4 The proportion of variance in ln-transformed Jaccard index of similarity explained by geographic distance and environmental difference. Environmental variables included difference between scores on the first four PC axes (principal components of eight climatic variables), difference in relief and difference in elevation between pairs of quadrats. Variance was partitioned among distance alone, difference in environmental variables alone and distance and environmental variables jointly. The total amount of variance explained in each latitudinal zone is given in Table 4 for the regression model combining spatial and environmental variables.

somewhat greater variance than distance alone. For Zone B, distance and environmental conditions jointly explain $63.2 \%$ of the variance and distance alone explains greater variance than environmental conditions alone. For Zone C, $44.0 \%$ of the explained variance is due to distance and environmental conditions jointly, and the amount explained by distance exceeds the amount explained by environmental conditions alone. For Zone $\mathrm{D}$, distance and environmental conditions jointly explain $46.2 \%$ of the variance, distance alone explains $29.3 \%$ of the variance and environmental conditions alone contribute little to the regression model. For Zone E, distance and environmental conditions jointly explain $32.5 \%$ of the variance and distance alone explains $17.3 \%$ of the variance, whereas environmental conditions alone explain just $7.6 \%$ of the variance.

Table 3 Mean and standard deviation of principal component (PC) scores within each latitudinal zone.

\begin{tabular}{|c|c|c|c|c|c|c|c|c|c|}
\hline \multirow[b]{2}{*}{ Zone } & \multirow[b]{2}{*}{$n$} & \multicolumn{2}{|l|}{ PC 1} & \multicolumn{2}{|l|}{ PC 2} & \multicolumn{2}{|l|}{ PC 3} & \multicolumn{2}{|l|}{ PC 4} \\
\hline & & Mean & $\mathrm{SD}$ & Mean & $\mathrm{SD}$ & Mean & SD & Mean & SD \\
\hline A & 50 & -3.202 & 1.280 & 0.881 & 1.460 & 0.157 & 0.974 & -0.168 & 0.544 \\
\hline B & 59 & -1.770 & 1.229 & 0.183 & 1.469 & 0.059 & 1.197 & 0.021 & 0.776 \\
\hline C & 58 & -0.420 & 0.828 & -0.277 & 1.228 & 0.037 & 0.935 & 0.118 & 0.833 \\
\hline D & 78 & 1.283 & 0.827 & -0.383 & 0.494 & -0.072 & 0.559 & -0.029 & 0.672 \\
\hline E & 68 & 2.777 & 0.832 & -0.132 & 0.578 & -0.116 & 0.438 & 0.038 & 0.598 \\
\hline
\end{tabular}

$n$, number of quadrats included. 
Table 4 Amount of variation (coefficient of determination $\times 100$ ) in natural logarithm of the Jaccard index $(\ln J)$ explained by different sets of explanatory variables in multiple regression models. All coefficients of determination are significant at $P<0.001$. Climate is represented by the first four principal components from Table 2; topography includes relief and elevation.

\begin{tabular}{lllllr}
\hline & \multicolumn{5}{l}{ Latitudinal zone } \\
\cline { 2 - 6 } Explanatory variable & A & B & C & D & E \\
\cline { 2 - 6 } & 82.8 & 79.6 & 62.1 & 75.5 & 49.8 \\
Spatial distance & 81.5 & 55.4 & 44.5 & 46.7 & 36.2 \\
Climate & 63.1 & 53.1 & 41.1 & 13.2 & 5.6 \\
Topography & 86.6 & 74.1 & 57.2 & 48.9 & 40.1 \\
$\begin{array}{l}\text { Climate and topography } \\
\text { Spatial distance, climate } \\
\quad \text { and topography }\end{array}$ & 93.5 & 90.5 & 75.3 & 78.2 & 57.4 \\
\hline
\end{tabular}

General latitudinal trends emerge from Fig. 4 but the trends are not consistently monotonic with latitude. The role of spatial distance alone increases in relation to the distances traversed by each latitudinal zone; Zone D traverses the greatest distance (about $6000 \mathrm{~km}$, see Fig. 2), and distance alone explains more of the variance $(29.3 \%)$ in Zone D than in any other zone. Distance and differences in environmental variables jointly explain more of the variance in $\ln J$ at lower latitudes, rising from less than $50 \%$ in zones C-E to more than $60 \%$ in zones A and B. Differences in the environmental variables alone explain less than $10 \%$ of the variance in $\ln J$ in zones $\mathrm{D}$ and $\mathrm{E}$ and more than $10 \%$ of the variance in zones A-C. From Table 4, it is evident that regression models based on distance alone or on differences in environmental conditions alone predict relatively large amounts of the variance in $\ln J$. But distance and differences in environmental conditions are strongly correlated; when both are included in a regression model their joint contribution dominates the explained variance.

\section{DISCUSSION}

\section{The beta-diversity gradient}

For the area of North America analysed, mammalian faunas show a decrease in zonal beta diversity with increasing latitude.
This trend is supported by the systematic shallowing of slope with latitude in the distance-decay plots in Figs 2 and 3(a) and the increase in mean $\ln J$ of zones with latitude (Table 1). At the levels of family and genus, the distance-decay plots reach an asymptote, reflecting the broad geographical distribution of most families and many genera (Fig. 2). The decrease in slope of $\ln J$ with latitude (Fig. 3a) has the same pattern as the decrease in slope of $\ln J$ with temperature and PC 1 for each latitudinal zone (Fig. 3b,c). This similarity indicates that 'latitude' is merely a proxy for underlying environmental gradients, including several measures of annual and seasonal temperature (Badgley \& Fox, 2000; Hawkins \& Diniz-Filho, 2004). Beta diversity is also strongly correlated with mean species richness per quadrat of each latitudinal zone (Fig. 3d).

Over most of North America, mammalian faunas at the species level become more dissimilar with greater distance apart. Zones A and B both show a steep decay of similarity with increasing distance. These temperate zones traverse considerable climatic and topographic heterogeneity from east to west. Mammalian faunas in these zones show higher species richness and ecological diversity and smaller geographical ranges west of the Great Plains (Pagel et al., 1991; Badgley \& Fox, 2000). Zone C is the only zone to show an asymptote in $\ln J$. The lowest values of $\ln J$ are about -1.2 in Zone $\mathrm{C}$, whereas the lowest values of $\ln J$ reach more negative values in the other four zones. Zone $\mathrm{C}$ spans the transition from temperate to boreal regions. The geographical ranges of North American mammals become substantially larger from Zone $\mathrm{C}$ northward. South of $c .48^{\circ} \mathrm{N}$, all species ranges comprise less than $20 \%$ of the area of North America, but north of $c .48^{\circ} \mathrm{N}$, many species ranges occupy more than $20 \%$ of the land area of North America (Fig. 5 in Pagel et al., 1991). This transition implies an increase in similarity among faunas of Zone $\mathrm{C}$ compared with those in zones A and B, as documented.

Longitudinally, zones D and $\mathrm{E}$ span greater maximum distances than do the more southerly zones. Both zones have faunas with greater dissimilarity than the most dissimilar faunas of Zone C. Zones $\mathrm{D}$ and $\mathrm{E}$ both traverse areas of Alaska that were unglaciated during the last ice age and supported a Beringian mammal fauna. After deglaciation, many Beringian species dispersed across the formerly glaciated regions, as immigrants also moved northward. A few Beringian species show little southern expansion after deglaciation, while the distribution of permafrost has limited the

Table 5 Mean and standard deviation of relief $(\mathrm{m})$, mean elevation $(\mathrm{m})$, mean annual temperature $\left({ }^{\circ} \mathrm{C}\right)$ and annual precipitation $(\mathrm{mm})$ of the quadrats in each latitudinal zone. Table S2 lists the mean and standard deviation of additional climatic variables.

\begin{tabular}{|c|c|c|c|c|c|c|c|c|c|}
\hline \multirow[b]{2}{*}{ Zone } & \multirow[b]{2}{*}{$n$} & \multicolumn{2}{|l|}{ Relief } & \multicolumn{2}{|c|}{ Elevation } & \multicolumn{2}{|c|}{ Temperature } & \multicolumn{2}{|c|}{ Precipitation } \\
\hline & & Mean & SD & Mean & SD & Mean & SD & Mean & SD \\
\hline A & 50 & 1469.9 & 1316.5 & 871.3 & 784.1 & 16.3 & 3.8 & 722.1 & 489.0 \\
\hline B & 59 & 1504.4 & 1177.4 & 1058.6 & 831.7 & 9.9 & 3.6 & 759.4 & 383.2 \\
\hline $\mathrm{C}$ & 58 & 1232.8 & 1153.2 & 770.3 & 513.5 & 4.9 & 2.5 & 755.6 & 336.5 \\
\hline $\mathrm{D}$ & 78 & 1238.1 & 1511.5 & 515.7 & 337.1 & -1.2 & 2.8 & 622.4 & 269.3 \\
\hline E & 68 & 777.8 & 748.8 & 384.2 & 249.4 & -7.4 & 3.2 & 424.8 & 272.4 \\
\hline
\end{tabular}

$n$, number of quadrats included. 
expansion of a number of northward immigrants, especially of rodents (Youngman, 1975). This combination of environmental history and modern environmental conditions may explain why more dissimilar faunas occur over the largest distances in zones $\mathrm{D}$ and $\mathrm{E}$ than in Zone C. Over shorter distances, Zone $\mathrm{C}$ shows greater dissimilarity among faunas than zones $\mathrm{D}$ and $\mathrm{E}$.

Spatial distance and physical aspects of the environment, separately or together, predict a greater fraction of the variance in turnover for zones at lower latitude than higher latitude. For Zone A, differences in climatic and topographic variables predict more variance in $\ln J$ than does spatial distance alone (Table 4). For zones B-D, spatial distance predicts more of the variance in $\ln J$ than do differences in climate and topography. However, when distance and environmental variables are evaluated simultaneously by variance partitioning (Fig. 4), the variance in $\ln J$ explained jointly by distance and environmental conditions exceeds that explained by distance alone or environmental conditions alone. Unmeasured factors have an increasingly large influence on beta diversity at higher latitudes. The drop in explained variance (Table 4, Fig. 4) is especially large between zones $\mathrm{A}$ and $\mathrm{B}$ and zones $\mathrm{C}-\mathrm{E}$, with a large drop also between Zone D and Zone E. Zones C-E cover the formerly glaciated region of North America. Time since deglaciation may influence beta diversity of zones C-E in ways that are not directly correlated with the variables included here. For example, Zone E contains much of the area of continuous permafrost (Brown, 1960), which limits species distributions, especially those of burrowers, in the high Arctic.

Beta diversity decreases little from Zone D to Zone E (the absolute slope being 0.169 for Zone D and 0.165 for Zone E) and the absolute mean of $\ln J$ for Zone $\mathrm{E}$ is slightly higher than those for zones C and D (Table 1). In Fig. 2, a cluster of quadrats separated by relatively short distances has lower values of $\ln J$ for both species and genera. This pattern does not occur in the other four zones (Fig. 2). Several factors may contribute to the patterns of Zone E. First, much of the westernmost area of Zone E was ice-free during the last glacial advance, as discussed above, and was a refugium for plants and animals. In contrast, the rest of Zone E was covered by an ice sheet for thousands of years. Some species from Beringia may have encountered barriers to dispersal into the eastern part of Zone E, resulting in quite dissimilar faunas at the two ends of the zone. Second, Hudson Bay separates Zone E into two parts, and this separation may have accentuated the faunal differences in pairs of quadrats from either side. Third, some species of Zone E are boreal species. These species are usually widely distributed in the boreal zone, but their ranges may have penetrated into only limited areas of Zone E, with different species ranges penetrating into different longitudinal regions of Zone E, resulting in little or no overlap of their ranges in Zone E. As a result, mammalian faunas separated by a short distance may be quite dissimilar in species composition. For areas with low species richness, differences of a few species in different quadrats may lead to a large dissimilarity (high negative $\ln J$ ) among the faunas, resulting in high species turnover in some species-poor areas (e.g. Gaston et al., 2007).

\section{Comparison with other studies of beta diversity}

Our results are consistent with those of earlier studies of North American mammal faunas, using different analytical approaches. Kaufman \& Willig (1998) and Rodríguez \& Arita (2004) documented higher turnover versus distance of non-volant mammals at lower latitudes of North America. In the present study, bats contribute to the beta-diversity gradient across zones A-E. Although Pagel et al. (1991) did not document turnover directly, their analysis of mammalian geographical range size in relation to latitude and longitude implies greater turnover at lower latitudes and western longitudes in North America. While previous studies, including the aforementioned ones, have documented species turnover of North American mammals, the present study has for the time demonstrated the contributions of distance and environmental conditions separately and jointly to spatial turnover of North American mammals.

In a similarly designed analysis of vascular plants, Qian \& Ricklefs (2007) found that beta diversity for vascular-plant assemblages decreases strongly with latitude. Regression models that included distance and climatic variables also explained a high proportion of the variance in $\ln J$; the amount of explained variance showed a different relationship with latitude than in this study. For their Zone D (approximately similar to Zone D in this study), spatial distance explained most of the variance in $\ln J$, whereas for mammals, distance and environmental factors jointly explain more variance than distance and environmental variables do separately (Fig. 4). Both studies demonstrate a decline in explained variance at higher latitudes. These similarities and differences suggest that mammal faunas and vascular-plant floras show broadly similar patterns of beta diversity over North America but that the spatial and environmental determinants of the pattern differ somewhat between these two groups.

Storch et al. (2005) demonstrated that the slope of the speciesarea relationship (SAR) for birds is shallower in areas of higher levels of available energy. A higher slope of the SAR reflects a faster accumulation of species with increasing sample area, and thus a greater rate of species turnover. Hence, their study implies that beta diversity is lower in areas with higher levels of available energy. In contrast, our study demonstrates that species turnover of mammals is greater in areas with higher ambient energy and decreases monotonically with decreasing ambient energy (measured as mean annual temperature; Fig. 3b).

Meta-analyses of beta diversity (e.g. Koleff et al., 2003; Soininen et al., 2007) have shown that beta-diversity patterns vary in relation to the spatial scale of the study, the metrics used to characterize turnover, the taxonomic group, major environment (marine versus terrestrial), as well as the specific region or continent. Comparisons within major taxonomic groups (e.g. montane and boreal floras, Nekola \& White, 1999; North American mammals, Rodríguez \& Arita, 2004) have also shown that beta-diversity patterns vary among different functional groups (e.g. volant versus non-volant mammals). In the present study, climatic and topographic features in combination with distance explain much of the variance in beta diversity for mammalian faunas in latitudinal zones. Turnover is also correlated with species richness (Fig. 3). 


\section{Insights about mechanisms}

Several covarying properties of mammalian faunas or environments provide insights into possible mechanisms underlying these patterns of spatial turnover. (1) Geographical range size. The increase in geographical range size with latitude, or Rapoport's rule, for a group is correlated with the latitudinal gradient in beta diversity for North American mammals. Pagel et al. (1991) documented a decrease in geographical range size at lower latitudes and higher longitudes for North American mammals. Together these trends locate the highest beta diversity in the south-western part of the area analysed - a region that includes the Colorado Plateau, the Great Basin and California. (2) Ecological structure of mammalian faunas. If geographical range size varies in relation to species body size or trophic habit, then geographical gradients in the ecological structure of mammalian faunas may also contribute to the continental pattern of beta diversity. The ecological structure of North American mammalian faunas shows considerable geographical variation (Badgley \& Fox, 2000): frugivores, aerial insectivores and terrestrial invertivores of small body size $(\leq 100 \mathrm{~g})$ dominate faunas at lower latitudes, whereas herbivorous and carnivorous species of larger body size are more prevalent at high latitudes. Granivores and herbivores of intermediate size are prevalent in desert and montane habitats of the west. (3) Environmental history. More than half of the area analysed was covered by massive ice sheets only 14,000 years ago. Areas with a much shorter duration of occupancy may exhibit lower species density and different patterns of spatial turnover. For North American mammals, the time since deglaciation has a measurable influence on extant species density in the formerly glaciated region (Hawkins \& Porter, 2003), implying a lag in recolonization. Furthermore, north-western Canada and eastern Alaska were recolonized by species from both the south and the west (Beringia), resulting in distinctive modern faunas unique to this region.

These covarying patterns suggest mechanistic hypotheses to elaborate and test. Ecological mechanisms include greater accommodation of species per unit area in regions with high topographic and resource heterogeneity; finer partitioning of resources among species at lower latitudes, as documented for African mammals (Hernández Fernández \& Vrba, 2005) and herbivorous insects (Dyer et al., 2007); narrower environmental tolerances of species in habitats with lower climatic seasonality, resulting in lower dispersal ability (e.g. Janzen, 1967); and the longevity of viable ecosystems for species to invade and inhabit. Evolutionary mechanisms include higher speciation rates either in more topographically complex landscapes or at lower latitude more generally (e.g. Rohde, 1992); higher extinction rates in areas of high environmental stress and massive ecosystem disturbance (from glacial cycles); and the long-term evolutionary interactions of mammalian faunas from different, historically separate regions (Simpson, 1964). Our results indicate that the combination of spatial distance and environmental factors (climate, topography) has more explanatory power than either physical dimension alone in predicting beta diversity. This combination is consistent with most of the mechanisms proposed above, and further studies are needed to evaluate the contributions of these different mechanisms.

\section{CONCLUSION}

The latitudinal gradient in beta diversity of North American mammals corresponds to a macroclimatic gradient of decreasing mean annual temperature and increasing seasonality of temperature from south to north. Spatial distance, differences in climatic conditions and differences in topography predict a substantial amount of the variation in beta diversity within latitudinal zones, and this predictive power declines towards higher latitudes. Most of the variance in spatial turnover is explained by distance and environmental differences jointly rather than distance, climate or topography separately. Faunas at the highest latitudes (Zone E) show slightly greater spatial turnover than do faunas from the adjacent zone to the south. This deviation from the primary latitudinal gradient in beta diversity probably reflects different post-glacial sources for recolonizing the formerly glaciated region at high latitudes and environmental barriers that limit the ranges of a few species at both the eastern and western ends of this broad latitudinal zone. The high predictive power of geographical distance, climatic conditions and topography on spatial turnover could result from the direct effects of physical limiting factors or from ecological and evolutionary processes that are also influenced by the geographical template.

\section{ACKNOWLEDGEMENTS}

We thank Bonnie Miljour for help in preparing Fig. 1 and two anonymous referees for helpful comments.

\section{REFERENCES}

Ahn, C.-H. \& Tateishi, R. (1994) Development of a global 30-min grid potential evapotranspiration data set. Photogrammetry and Remote Sensing, 33, 12-21.

Arita, H.T. (1997) The non-volant mammal fauna of Mexico: species richness in a megadiverse country. Biodiversity and Conservation, 6, 787-795.

Badgley, C. \& Fox, D.L. (2000) Ecological biogeography of North American mammals: species density and ecological structure in relation to environmental gradients. Journal of Biogeography, 27, 1437-1467.

Barbour, M.G. \& Billings, W.D. (1999) North American terrestrial vegetation, 2nd edn. Cambridge University Press, Cambridge, UK.

Brown, R.J.E. (1960) The distribution of permafrost and its relation to air temperature in Canada and the U.S.S.R. Arctic, 13, 163-177.

Condit, R., Pitman, N., Leigh, E.G., Chave, J., Terborgh, J., Foster, R.B., Nuñez, P., Aguilar, S., Valencia, R., Villa, G., Muller-Landau, H.C., Losos, E. \& Hubbell, S.P. (2002) Betadiversity in tropical forest trees. Science, 295, 666-669.

Currie, D.J. (1991) Energy and large-scale patterns of animal- and plant-species richness. The American Naturalist, 137, 27-49. 
Dyer, L.A., Singer, M.S., Lill, J.T., Stireman, J.O., Gentry, G.L., Marquis, R.J., Ricklefs, R.E., Greeney, H.F., Wagner, D.L., Morais, H.C., Diniz, I.R., Kursar, T.A. \& Coley, P.D. (2007) Host specificity of Lepidoptera in tropical and temperate forests. Nature, 448, 696-700.

Gaston, K.J. (2000) Global patterns in biodiversity. Nature, 405, 220-227.

Gaston, K.J., Davies, R.G., Orme, C.D.L., Olson, V.A., Thomas, G.H., Ding, T.-S., Rasmussen, P.C., Lennon, J.J., Bennett, P.M., Owens, I.P.F. \& Blackburn, T.M. (2007) Spatial turnover in the global avifauna. Proceedings of the Royal Society of London B, 274, 1567-1574.

Hall, E.R. (1981) The mammals of North America, 2nd edn. John Wiley, New York, NY.

Hawkins, B.A. \& Diniz-Filho, J.A.F. (2004) 'Latitude' and geographic patterns in species richness. Ecography, 27, 268-272.

Hawkins, B.A. \& Porter, E.E. (2003) Relative influences of current and historical factors on mammal and bird diversity patterns in deglaciated North America. Global Ecology and Biogeography, 12, 475-481.

Hernández Fernández, M. \& Vrba, E.S. (2005) Rapoport effect and biomic specialization in African mammals: revisiting the climatic variability hypothesis. Journal of Biogeography, 32, 903-918.

Hillebrand, H. (2004) On the generality of the latitudinal diversity gradient. The American Naturalist, 163, 192-211.

Hutchinson, G.E. (1959) Homage to Santa Rosalia or why are there so many kinds of animals? The American Naturalist, 93, 145-159.

Janis, C.M., Damuth, J. \& Theodor, J.M. (2002) The origins and evolution of the North American grassland biome: the story from the hoofed mammals. Palaeogeography, Palaeoclimatology, Palaeoecology, 177, 183-198.

Janzen, D.H. (1967) Why mountain passes are higher in the tropics. The American Naturalist, 101, 233-249.

Jernvall, J. \& Fortelius, M. (2002) Common mammals drive the evolutionary increase of hypsodonty in the Neogene. Nature, 417, 538-540.

Kaufman, D.M. (1995) Diversity of New World mammals: universality of the latitudinal gradient of species and bauplans. Journal of Mammalogy, 76, 322-334.

Kaufman, D.M. \& Willig, M.R. (1998) Latitudinal patterns of mammalian species richness in the New World: the effect of sampling method and faunal group. Journal of Biogeography, 25, 795-805.

Koleff, P., Lennon, J.J. \& Gaston, K.J. (2003) Are there latitudinal gradients in species turnover? Global Ecology and Biogeography, 12, 483-498.

Legendre, P. \& Legendre, L. (1998) Numerical ecology, 2nd edn. Elsevier, Amsterdam.

Legendre, P., Lapointe, F.-J. \& Casgrain, P. (1994) Modeling brain evolution from behavior: a permutational regression approach. Evolution, 48, 1487-1499.

Mittelbach, G.G., Schemske, D.W., Cornell, H.V., Allen, A.P., Brown, J.M., Bush, M.B., Harrison, S.P., Hurlbert, A.H., Knowlton, N., Lessios, H.A., McCain, C.M., McCune, A.R.,
McDade, L.A., McPeek, M.A., Near, T.J., Price, T.D., Ricklefs, R.E., Roy, K., Sax, D.F., Schluter, D., Sobel, J.M. \& Turelli, M. (2007) Evolution and the latitudinal diversity gradient: speciation, extinction and biogeography. Ecology Letters, 10, 315-331.

Nekola, J.C. \& White, P.S. (1999) The distance decay of similarity in biogeography and ecology. Journal of Biogeography, 26, 867878.

New, M., Hulme, M. \& Jones, P. (1999) Representing twentiethcentury space-time climate variability. Part I: development of a 1961-90 mean monthly terrestrial climatology. Journal of Climate, 12, 829-856.

Pagel, M.D., May, R.M. \& Collie, A.R. (1991) Ecological aspects of the geographical distribution and diversity of mammalian species. The American Naturalist, 137, 791-815.

Pianka, E.R. (1966) Latitudinal gradients in species diversity: a review of concepts. The American Naturalist, 100, 33-46.

Qian, H. \& Ricklefs, R.E. (2007) A latitudinal gradient in largescale beta diversity for vascular plants in North America. Ecology Letters, 10, 737-744.

Qian, H., Ricklefs, R.E. \& White, P.S. (2005) Beta diversity of angiosperms in temperate floras of eastern Asia and eastern North America. Ecology Letters, 8, 15-22.

Rodríguez, P. \& Arita, H.T. (2004) Beta diversity and latitude in North American mammals: testing the hypothesis of covariation. Ecography, 27, 547-556.

Rohde, K. (1992) Latitudinal gradients in species diversity: the search for the primary cause. Oikos, 65, 514-527.

Rosenzweig, M.L. (1995) Species diversity in space and time. Cambridge University Press, Cambridge, UK.

Simpson, G.G. (1964) Species density of North American recent mammals. Systematic Zoology, 13, 57-73.

Soininen, J., McDonald, R. \& Hillebrand, H. (2007) The distance decay of similarity in ecological communities. Ecography, 30, $3-12$.

Stevens, G.C. (1989) The latitudinal gradient in geographical range: how so many species coexist in the tropics. The American Naturalist, 133, 240-256.

Stevens, R.D. \& Willig, M.R. (2002) Geographical ecology at the community level: perspectives on the diversity of New World bats. Ecology, 83, 545-560.

Storch, D., Evans, K.L. \& Gaston, K.J. (2005) The species-areaenergy relationship. Ecology Letters, 8, 487-492.

Svenning, J.-C. \& Skov, F. (2004) Limited filling of the potential range in European tree species. Ecology Letters, 7, 565-573.

Whittaker, R.H. (1977) Evolution of species diversity in land communities. Evolutionary Biology, 10, 1-67.

Willig, M.R., Kaufman, D.M. \& Stevens, R.D. (2003) Latitudinal gradients in biodiversity: pattern, process, scale, and synthesis. Annual Review of Ecology, Evolution, and Systematics, 34, 273309.

Wilson, D.E. \& Reeder, D.M. (1993) Mammal Species of the World: a taxonomic and geographic reference, 2nd edn. Smithsonian Institution Press, Washington, DC.

Youngman, P.M. (1975) Mammals of the Yukon Territory. Publications in Zoology, No. 10. National Museums of Canada, Ottawa, Ontario. 


\section{SUPPORTING INFORMATION}

Additional Supporting Information may be found in the online version of this article:

Table S1 Coefficients and standardized coefficients of variables used in five regression models for each latitudinal zone.

Table S2 Average values and standard deviations of climate data for the quadrats in each latitudinal zone.

Please note: Wiley-Blackwell are not responsible for the content or functionality of any supporting materials supplied by the authors. Any queries (other than missing material) should be directed to the corresponding author for the article.

\section{BIOSKETCHES}

Hong Qian is interested in searching for and interpreting large-scale patterns and processes of biodiversity and biogeography. In particular, he is interested in understanding the relative roles of historical and modern factors in determining the patterns in biodiversity.

Catherine Badgley is interested in palaeoecology of mammals, taphonomy, Miocene mammals of Indo-Pakistan and biogeography.

David L. Fox uses stable isotopes of biogenic and sedimentary materials to answer questions in palaeobiology and palaeoclimatology, analyses the role of stratigraphic data in phylogenetic analysis through the use of computer simulated evolutionary histories, and studies the ecological biogeography of modern mammals in relation to the spatial variation in climate.

Editor: Tim Blackburn 